\title{
Radiolabeling of cidofovir with technetium-99m and biodistribution studies
}

\author{
Raquel Gregorio Arribada ${ }^{\circledR 1}$, Nara Caroline Pereira², Valbert Nascimento Cardoso ${ }^{2}$, \\ Armando da Silva Cunha Júnior ${ }^{1}$, André Luís Branco de Barros ${ }^{2 *}$ \\ ${ }^{1}$ Department of Pharmaceutical Products, Faculty of Pharmacy, Federal University of Minas \\ Gerais, Belo Horizonte, Minas Gerais, Brazil, ${ }^{2}$ Department of Clinical and Toxicological Analyses, \\ Faculty of Pharmacy, Federal University of Minas Gerais, Belo Horizonte, Minas Gerais, Brazil
}

\begin{abstract}
Radiolabeling cidofovir with technetium-99m $\left({ }^{99 \mathrm{~m}} \mathrm{Tc}-\mathrm{CDV}\right)$ is an innovative procedure that enables real-time monitoring of the drug. Essays were performed in vitro, showing high radiolabel stability within $24 \mathrm{~h}$. Blood clearance, biodistribution studies, and scintigraphic images were performed in healthy mice in order to evaluate the profile of the drug in vivo. ${ }^{99 \mathrm{~m} T c-C D V}$ showed biphasic blood circulation time and significant kidney uptake, indicating that ${ }^{99 \mathrm{~m}} \mathrm{Tc}-\mathrm{CDV}$ is preferentially eliminated by the renal route. Bones also showed important uptake throughout the experiment. In summary, cidofovir was successfully labeled with technetium-99m and might be used in further studies to track the drug.
\end{abstract}

Keywords: Cidofovir. Radiotracer. Technetium-99m. Biodistribution. Scintigraphic imaging.

\section{INTRODUCTION}

Cidofovir (CDV) is a cytosine nucleotide analogue with broad-spectrum anti-DNA virus activity, including human cytomegalovirus (HCMV), which was first reported in 1986 and approved by the US Food and Drug Administration (FDA), under the trade name of Vistide ${ }^{\circledR}$, for the systemic treatment of HCMV retinitis in people with acquired immunodeficiency syndrome (Jackowska, 2018; Broekema, Dikkers, 2008; Andrei, Snoeck, 2010). Currently, CDV has been used to treat some viral infections, but mainly recurrent respiratory papillomatosis (RRP), which is a chronic disease caused by Human Papilloma Virus (HPV) and affects mainly children and teenagers. The use of antivirals as adjuvants on the treatment of RRP has been shown to be more effective in the control of laryngeal lesions, with cidofovir (CDV) being the most used off-

*Correspondence: A. L. B. Barros, Faculdade de Farmácia, Universidade Federal de Minas Gerais, Av. Antônio Carlos, 6627, 31270-901, Belo Horizonte, Minas Gerais, Brazil. Phone: +55 (31) 3409 6840. Email: brancodebarros@yahoo.com.br label drug currently used (Tran, Galt, Bashirzadeh, 2018; Rasmussen et al., 2017; Carifi et al., 2015). Its mechanism of action is based on the inhibition of the viral DNA polymerase, followed by incorporation into the growing DNA chain, resulting in low efficiency of DNA transcription (Fusconi et al., 2014). Although few side effects of CDV have been reported, some of them are described as rash, headache, local inflammation, and potential nephrotoxicity; in animal studies, concerns have been raised about carcinogenicity (Coomes, 2018; Sahota et al., 2011).

Labeling molecules with radioisotopes, such as technetium-99m $\left({ }^{99 m} \mathrm{Tc}\right)$, enables us to determine, in real-time, the radiometal complex biodistribution (Snehalatha et al., 2008). This method is an important tool in studying pharmacokinetics, once it permits direct visualization and quantification of the drug. ${ }^{99 \mathrm{~m}} \mathrm{Tc}$ is the commonly used radioisotope due to its physical and chemical characteristics, such as low energy (140 $\mathrm{KeV}$ ), large availability in nuclear medicine laboratories and inexpensive isotope cost (Fernandes et al., 2015; De Barros et al., 2013; Yang et al., 2003). 


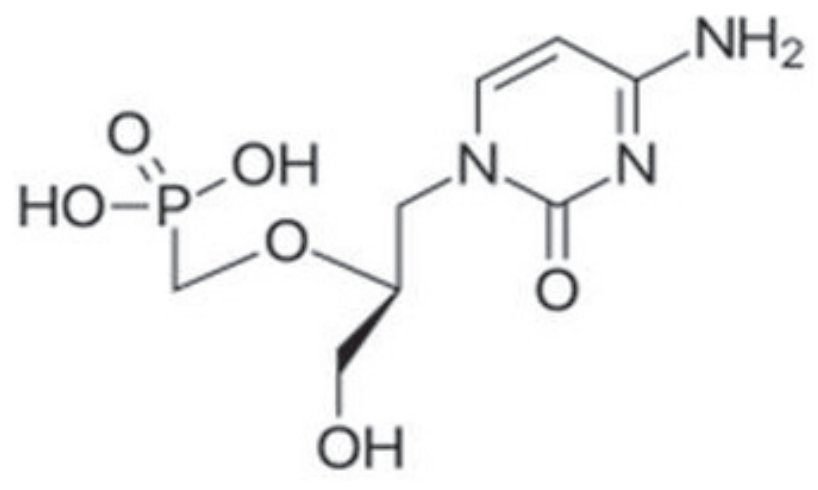

FIGURE 1 - Chemical structure of cidofovir.

Technetium- $99 \mathrm{~m}$ is obtained from the Molybdenum generator as sodium pertechnetate $\left({ }^{99 \mathrm{~m}} \mathrm{Tc}-\mathrm{NaTcO} 4\right)$, and the ion ${ }^{99 \mathrm{~m}} \mathrm{TcO} 4$ - is chemically nonreactive. Therefore, prior reduction of ${ }^{99 \mathrm{~m}} \mathrm{Tc}$ from the $7+$ state to a lower oxidation state, most commonly to $4+$, is required, and among various reducing agents, stannous chloride $(\mathrm{SnCl} 2 \mathrm{H} 2 \mathrm{O})$ is often the chosen one in preparations of ${ }^{99 \mathrm{~m}} \mathrm{Tc}$-labeled compounds. The reactive species usually combine with chelating agents, so that the chelating agent donates lone pairs of electrons to form coordinate covalent bonds (Papagiannopoulou, 2017). CDV has several functional groups, such as -NH2, -O-, -POOH (Figure 1), which are able to donate pairs of electrons and form complexes with ${ }^{99 \mathrm{~m}} \mathrm{Tc}$. Unlike in nucleoside phosphates, in acyclic nucleoside phosphonates, such as $\mathrm{CDV}$, the phosphonate group is already attached to the nucleoside analog, resulting in the formation of a phosphonomethyl ether (-P-C-O-), which confers resistance to esterases (Andrei \& Snoeck, 2010). This fact is especially important to keep the drug molecule integrity since phosphonates are very common chelator to ${ }^{99 \mathrm{~m}} \mathrm{Tc}$ (Saeed et al., 2017). Thus, CDV might be a potential target to electron-deficient radiometals, such as ${ }^{99 \mathrm{~m}} \mathrm{Tc}$, producing a stable complex that will allow tracking the in vivo behavior of CDV.

Even though there are some pharmacokinetics studies of CDV already published in the literature, radiolabeling CDV with ${ }^{99 \mathrm{~m}} \mathrm{Tc}$ provides a new tool for understanding this drug's behavior in the body, as well as obtaining a general overview of its biodistribution in real time by scintigraphy. Developing a bioanalytical HPLC method to quantify CDV in vivo can be quite challenging, especially when the purpose of the study is to screen the drug after intravenous administration, and not only in a specific organ or tissue, which justifies the development of a radiotracer capable of monitoring CDV to better understand its pharmacokinetic profile.

Therefore, the aim of this study was to label CDV with ${ }^{99 \mathrm{~m}} \mathrm{Tc}$ and evaluate its in vitro stability. In addition, biodistribution studies and scintigraphic imaging were carried out in healthy mice in order to determine in vivo ${ }^{99 m}$ Tc-CDV's fate.

\section{MATERIAL AND METHODS}

\section{Material}

Cidofovir hydrate (CDV), $>98.0 \%$, was purchased from Sigma-Aldrich (São Paulo, Brazil). ${ }^{99 \mathrm{~m} T c}$ was obtained from an alumina-based $99 \mathrm{Mo} /{ }^{99 \mathrm{~m}} \mathrm{Tc}$ generator. All reagents (analytical grade), including $\mathrm{SnCl} 2.2 \mathrm{H} 2 \mathrm{O}$ 98.0\%, were purchased from Sigma-Aldrich (São Paulo, Brazil). Healthy 4-6-week-old female Swiss mice, 20g, were acquired from CEBIO-UFMG (Belo Horizonte, Brazil). All animal studies were approved by the local Ethics Committee for Animal Experiments (CEUA/ UFMG), under protocol number 184/2017.

\section{In vitro studies}

\section{Radiolabeling procedure}

CDV (1.0 mg) was dissolved in $300 \mu \mathrm{L}$ of $\mathrm{NaCl}$ $0.9 \%(w / v)$. An aliquot of $100 \mu \mathrm{L}$ of a $\mathrm{SnCl} 2.2 \mathrm{H} 2 \mathrm{O}$ $98.0 \%$ solution in $\mathrm{HCl} 0.25 \mathrm{M}$ was added and the $\mathrm{pH}$ was adjusted to 7.0 with a $1 \mathrm{M} \mathrm{NaOH}$ solution. The vacuum was applied in the vials and an aliquot of $0.1 \mathrm{~mL}$ of $\mathrm{Na}^{99 \mathrm{~m}} \mathrm{TcO} 4(37 \mathrm{MBq})$ was added. The final solution was kept at room temperature for 15 minutes to complete the radiolabeling procedure.

\section{Radiochemical purity evaluation}

The radiolabeled efficiencies were analyzed by ascending thin layer chromatography (TLC) on silica gel strips (TLC-SG; Merck, Darmstadt, Germany) as the stationary phase and acetone as the mobile phase. In this system, free ${ }^{99 \mathrm{~m}} \mathrm{TcO} 4-$ showed $\mathrm{Rf}=1$, while ${ }^{99 \mathrm{~m}} \mathrm{TcO} 2{ }^{99 \mathrm{~m}} \mathrm{Tc}-\mathrm{CDV}$ showed $\mathrm{Rf}=0$. The amount of free ${ }^{99 \mathrm{~m}} \mathrm{TcO} 4-$ was determined by measuring the radioactivity of the strips in a gamma counter (Wallac 
Wizard 1470-020 Gamma Counter; PerkinElmer Inc., Waltham, Massachusetts, USA). The solution was purified from ${ }^{99 \mathrm{~m}} \mathrm{TcO} 2$ using a $0.22 \mu \mathrm{m}$ syringe filter (6). The analysis was performed in triplicate. The HPLC analysis was conducted using a previously validated method for specificity, linearity, precision, and accuracy, adapted from Santoyo et al. (2002), using an Agilent ${ }^{\circledR}$ with a DAD detector at a wavelength of $274 \mathrm{~nm}$. HPLC mobile phase consisted of a mixture of a $1,5 \mathrm{mM}$ tetrabutylammonium phosphate and a 3,5 $\mathrm{mM}$ monobasic sodium phosphate buffer solution with acetonitrile 99.9\% (97:3 v/v), pH=6.0. A Purospher ${ }^{\circledR}$ C-18 column $(5.0 \mu \mathrm{m}, 4.6 \mathrm{~mm} \times 250 \mathrm{~mm})$ was used at a rate of $1.0 \mathrm{~mL} / \mathrm{min}$, under isocratic elution, with an injection volume of $10 \mu \mathrm{L}$. Samples were collected every 10 seconds, in different tubes, for $25 \mathrm{~min}$, and radiation was measured in a gamma counter.

\section{In vitro stability}

TLC-SG was used to estimate the stability ${ }^{99 \mathrm{~m}} \mathrm{Tc}-\mathrm{CDV}$ in the presence of saline $0.9 \%(\mathrm{w} / \mathrm{v})$ and mouse plasma. To determine the saline stability, the labeled solution was kept at room temperature and the radiochemical stability was determined from samples taken at 1, 2, 4, 6 and $24 \mathrm{~h}$ after incubation. Plasma stability was assessed by incubating a volume of $90 \mu \mathrm{L}$ of the ${ }^{99 \mathrm{~m}} \mathrm{Tc}-\mathrm{CDV}$ solution, under agitation, at $37^{\circ} \mathrm{C}$ with $1.0 \mathrm{~mL}$ of fresh mouse plasma. EDTA was used as an anticoagulant. Radiochemical stability was determined from samples taken at 1, 2, 4, 6 and $24 \mathrm{~h}$ after incubation. Both stability analyzes were performed in triplicate.

\section{Partition coefficient}

Aliquots of $0.1 \mathrm{~mL}$ of the ${ }^{99 \mathrm{~m}} \mathrm{Tc}-\mathrm{CDV}(0.37 \mathrm{MBq})$ were added to tubes containing $2.0 \mathrm{~mL}$ of $n$-octanol/ water (1:1). The tubes were submitted to vigorous stir for $5 \mathrm{~min}$. After phase separation, aliquots of 0.5 $\mathrm{mL}$ from each phase were collected and radioactivity was measured in a gamma counter. The analysis was performed in triplicate. Partition coefficient was determined according to the equation:

Partition coefficient $=\log \frac{\text { organic phase }(\mathrm{cpm}) \times 100}{\text { aquous phase }(\mathrm{cpm})}$

\section{Plasma protein binding}

Plasma protein binding profile was estimated by the protein precipitation method. An aliquot of $45 \mu \mathrm{L}$ of ${ }^{99 \mathrm{~m}} \mathrm{Tc}-\mathrm{CDV}$ was added to 3 different vials containing 500 $\mu \mathrm{L}$ of fresh mouse plasma and incubated at $37^{\circ} \mathrm{C}$, under agitation. EDTA $99.9 \%$ was used as an anticoagulant. At $30 \mathrm{~min}, 1$ and $4 \mathrm{~h}$ after incubation, an aliquot of $1.5 \mathrm{~mL}$ of acetonitrile was added to each vial for plasma protein precipitation. Samples were centrifuged at 5000xg for $3 \mathrm{~min}$, and the radioactivity of supernatant and pellet was measured in a gamma counter. The analysis was performed in triplicate. Percent of protein binding was calculated according to the equation:

$\%$ Plasma protein binding $=\frac{\text { precipitate } \times 100}{(\text { supernatant }+ \text { precipitate })}$

\section{Animal studies}

\section{Blood clearance}

${ }^{99 \mathrm{~m}} \mathrm{Tc}-\mathrm{CDV}$ was administrated to each mouse $(\mathrm{n}=7)$, previously anesthetized with a mixture of xylazine (15 $\mathrm{mg} / \mathrm{kg}$ ) and ketamine $(80 \mathrm{mg} / \mathrm{kg})$, through the tail vein, and a small incision was made in the distal tail to facilitate rapid and reliable blood collection. Blood samples $(\sim 20 \mu \mathrm{L}$ each) were collected at $1,5,10,15,30,45,60,90,120$ and 240 min after administration. Each sample was weighed and the radioactivity was measured with an automatic scintillation counter. The percentage of injected activity per gram $(\% \mathrm{ID} / \mathrm{g})$ and its mean $\pm \mathrm{SD}$ in each sample were determined, and the data were plotted as a function of time. Blood clearance analysis was performed using GraphPad PRISM, version 5.00 software (GraphPad Softwar Inc., La Jolla, California, USA).

\section{Ex vivo biodistribution}

Aliquots of $3.7 \mathrm{MBq}$ of ${ }^{99 \mathrm{~m}} \mathrm{Tc}-\mathrm{CDV}$ were injected intravenously into the tail vein of Swiss mice $(n=7)$. At 1 and $4 \mathrm{~h}$ after injection, mice were anesthetized with a mixture of xylazine $(15 \mathrm{mg} / \mathrm{kg})$ and ketamine $(80$ $\mathrm{mg} / \mathrm{kg}$ ). Blood, spleen, kidneys, stomach, lungs, heart, intestines, muscle, bone, thyroid, brain and liver were removed and placed in pre-weighed plastic test tubes. The radioactivity was measured by an automatic scintillation counter. A standard dose containing the same injected 
amount was counted simultaneously in a separated tube, which was defined as $100 \%$ radioactivity. The results were expressed as the percentage of injected dose per gram of tissue $(\% \mathrm{ID} / \mathrm{g})$.

\section{Scintigraphic images}

Aliquots of $3.7 \mathrm{MBq}$ of ${ }^{99 \mathrm{~m}} \mathrm{Tc}-\mathrm{CDV}$ were injected intravenously into the tail vein of Swiss mice $(n=7)$. Mice were anesthetized and then horizontally placed under the collimator of a gamma camera (Mediso, Budapest, Hungary) coupled with a low-energy highresolution collimator. Images were acquired at 1 and 4 $\mathrm{h}$ after injection using a 256x256x16 matrix size, with a $20 \%$ energy window set at $140 \mathrm{Kev}$ for a period of 300 s each.

\section{Statistical analysis}

All data are expressed as mean $\pm \mathrm{SD}$ and they were analyzed by GraphPad PRISM, version 5.0 software (GraphPad Software Inc.).

\section{RESULTS}

\section{Radiochemical purity and in vitro stability}

${ }^{99 m}$ Tc-CDV was efficiently labeled with technetium$99 \mathrm{~m}$, showing, after filtration in a $0.22 \mu \mathrm{m}$ sterile filter, radiochemical yields of $99.3 \pm 0.2 \%(n=3)$. Results obtained by HPLC analysis corroborate with TLC data, as demonstrated in Figure 2. The radiation peak (Figure 2A) occurs at almost the same retention time of ${ }^{99 \mathrm{~m}} \mathrm{Tc}-$ CDV obtained in the chromatogram (Figure 2B), which indicates a single ${ }^{99 m} \mathrm{Tc}-$ labeled species, indicating similar radiochemical yields than those obtained by TLC. Radiochemical stability was also performed at $1,2,4,6$ and $24 \mathrm{~h}$ post-incubation in saline, at room temperature, or in mouse plasma, at $37^{\circ} \mathrm{C}$. The complex ${ }^{99 \mathrm{~m}} \mathrm{Tc}-\mathrm{CDV}$ remains stable, in both media, even after long periods, as shown in Figure 3.

\section{Partition coefficient}

The partition coefficient of ${ }^{99 \mathrm{~m}} \mathrm{Tc}-\mathrm{CDV}$ was determined by the ratio between n-octanol and water, and the $\log \mathrm{P}$ found for ${ }^{99 \mathrm{~m}} \mathrm{Tc}-\mathrm{CDV}$ was in the hydrophilic range $(\log \mathrm{P}=-1.39 \pm 1.9)(\mathrm{n}=3)$.

\section{Plasma protein binding}

High plasma protein binding was observed for ${ }^{99 \mathrm{~m}} \mathrm{Tc}-\mathrm{CDV}$. At $30 \mathrm{~min}$ post-incubation, $45.7 \pm 1.5 \%$ of ${ }^{99 \mathrm{~m}} \mathrm{Tc}-\mathrm{CDV}$ was bound to plasma protein. After $1 \mathrm{~h}, 90.1$ $\pm 0.8 \%$ of binding was reached, and the level of protein binding was kept at $91.1 \pm 1.0 \%$ after $4 \mathrm{~h}(\mathrm{n}=3)$.

\section{Animal studies}

\section{Blood clearance}

The injection of ${ }^{99 \mathrm{~m}} \mathrm{Tc}-\mathrm{CDV}$ through the tail vein of the mice showed a long blood clearance of the complex, with a biphasic half-life profile. Figure 4 exhibits the distribution half-life of $2.3 \mathrm{~min}$ and the elimination halflife of $227.1 \mathrm{~min}$ and an area under the curve of $2850 \%$ $\operatorname{ID} / \min (\mathrm{n}=7)$.

\section{Ex vivo biodistribution}

Figure 5 shows the biodistribution of ${ }^{99 \mathrm{~m} T c-C D V}$ at 1 and $4 \mathrm{~h}$ after intravenous administration in healthy mice. At both times, maximum uptake was observed in the kidneys, followed by the bones. Moreover, important uptake was also observed in the small intestine and the liver, indicating that intestinal route contributes to the excretion of ${ }^{99 \mathrm{~m}} \mathrm{Tc}-\mathrm{CDV}$. No significant uptake was observed in other organs $(n=7)$.

\section{Scintigraphic images}

Scintigraphic imaging exhibited a similar profile to the one presented by the biodistribution studies, as shown in Figure 6. The image of 1 h shows a strong signal in the abdominal area, most likely as a result of the high uptake by the kidneys, small intestine, and liver. At the time of $4 \mathrm{~h}$, signal strength decreases, due to drug clearance. In addition, in both images, it is noticeable the signal emitted by bone uptake (arrows) $(n=7)$.

\section{DISCUSSION}

Cidofovir is a cytidine analog that suppresses viral replication by the selective inhibition of DNA synthesis, being active against all kinds of herpesvirus, cytomegalovirus, adenovirus, polyomavirus and human papillomavirus (Sala, Suriol, Montero, 2017). Even though CDV is not licensed for this indication, 
A

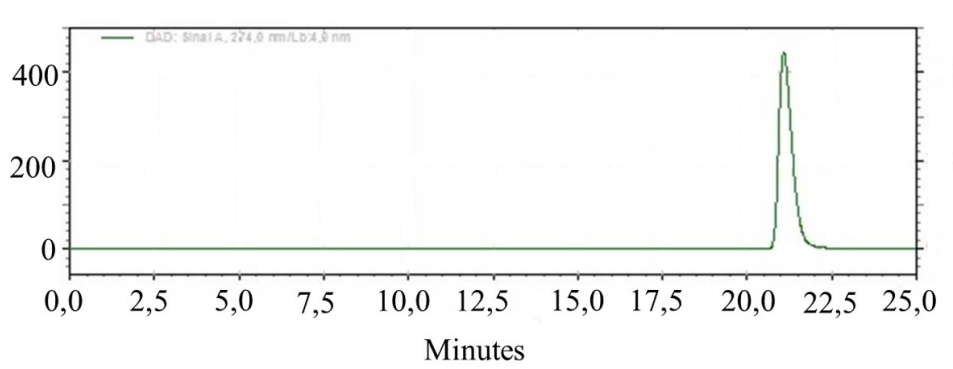

B

CPM

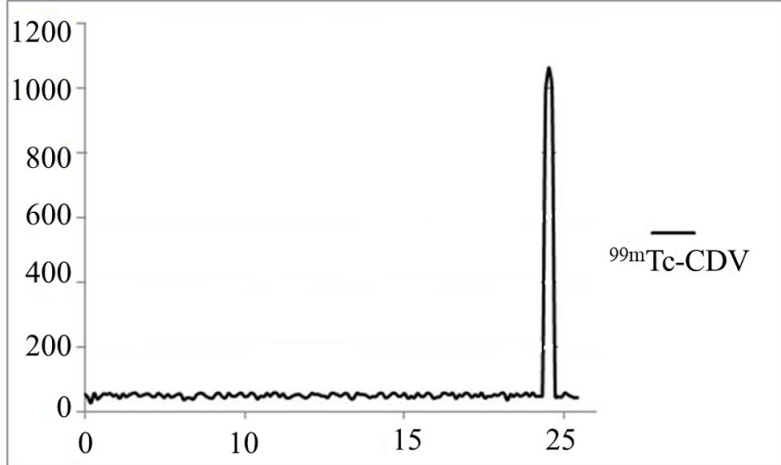

Minutes

FIGURE 2 - Reverse phase HPLC chromatogram (a) and radiochromatogram (b) of ${ }^{99 m} \mathrm{Tc}-\mathrm{CDV}$.

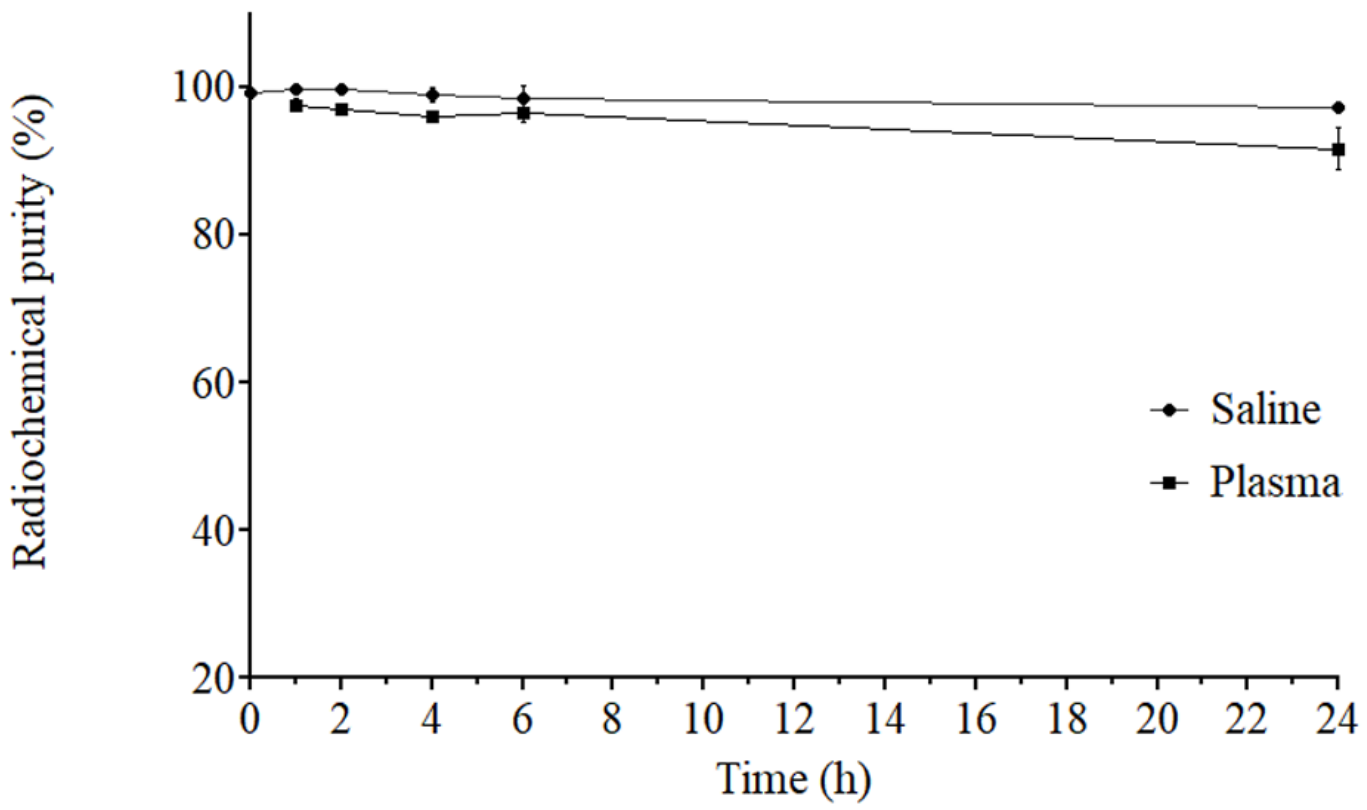

FIGURE 3 - In-vitro stability of ${ }^{99 \mathrm{~m}} \mathrm{Tc}-\mathrm{CDV}$ as a function of time in the presence of saline, at room temperature, and in the presence of mouse plasma, at $37^{\circ} \mathrm{C}(\mathrm{n}=3)$. 


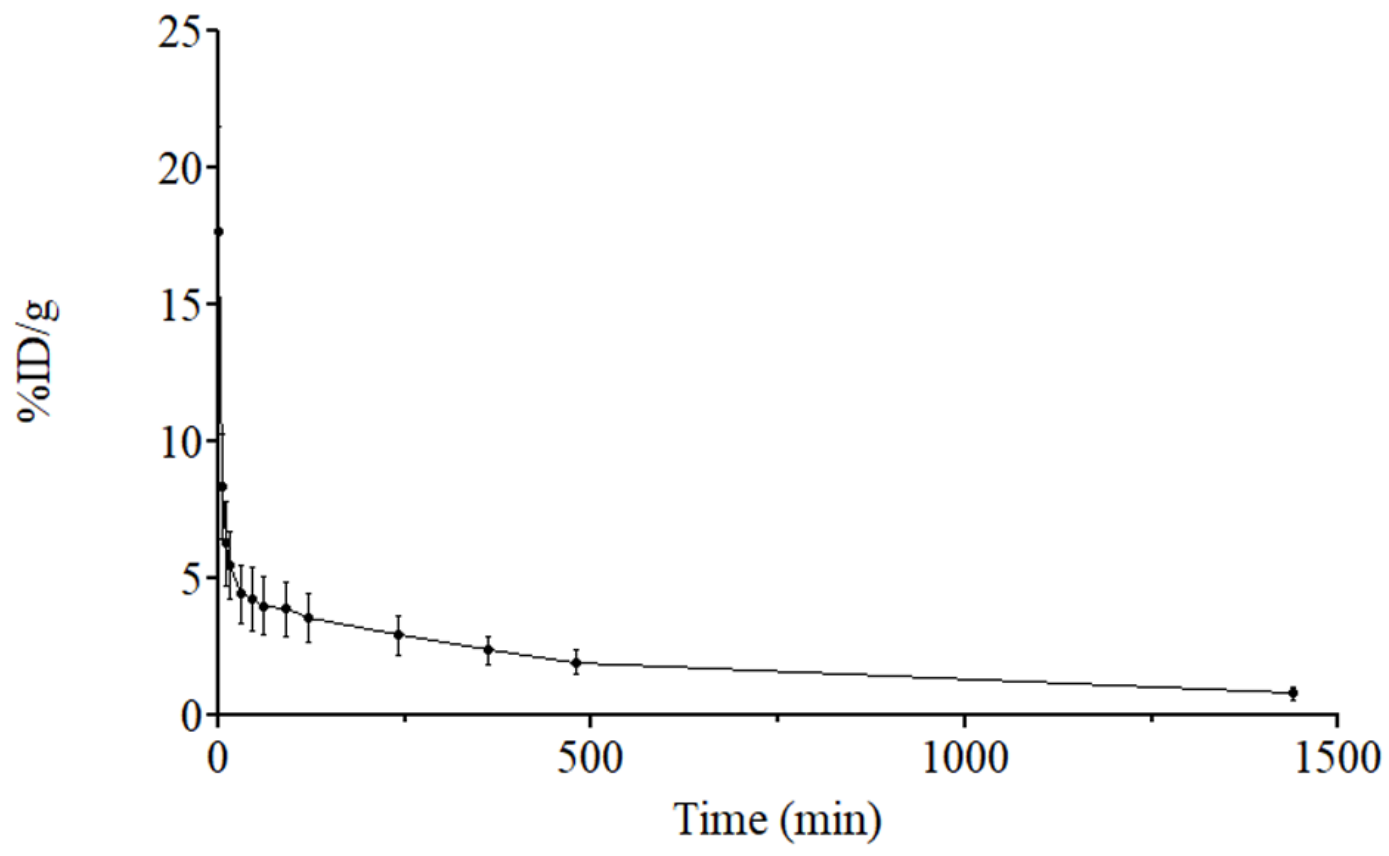

FIGURE 4 - Blood clearance of ${ }^{99 \mathrm{~m}} \mathrm{Tc}-\mathrm{CDV}$ in healthy female SWISS mice. All data are the mean percentage $(\mathrm{n}=7)$ of the injected dose of ${ }^{99 \mathrm{~m}} \mathrm{Tc}-\mathrm{CDV}$ per gram of blood, $\pm \mathrm{SD}$ of the mean.

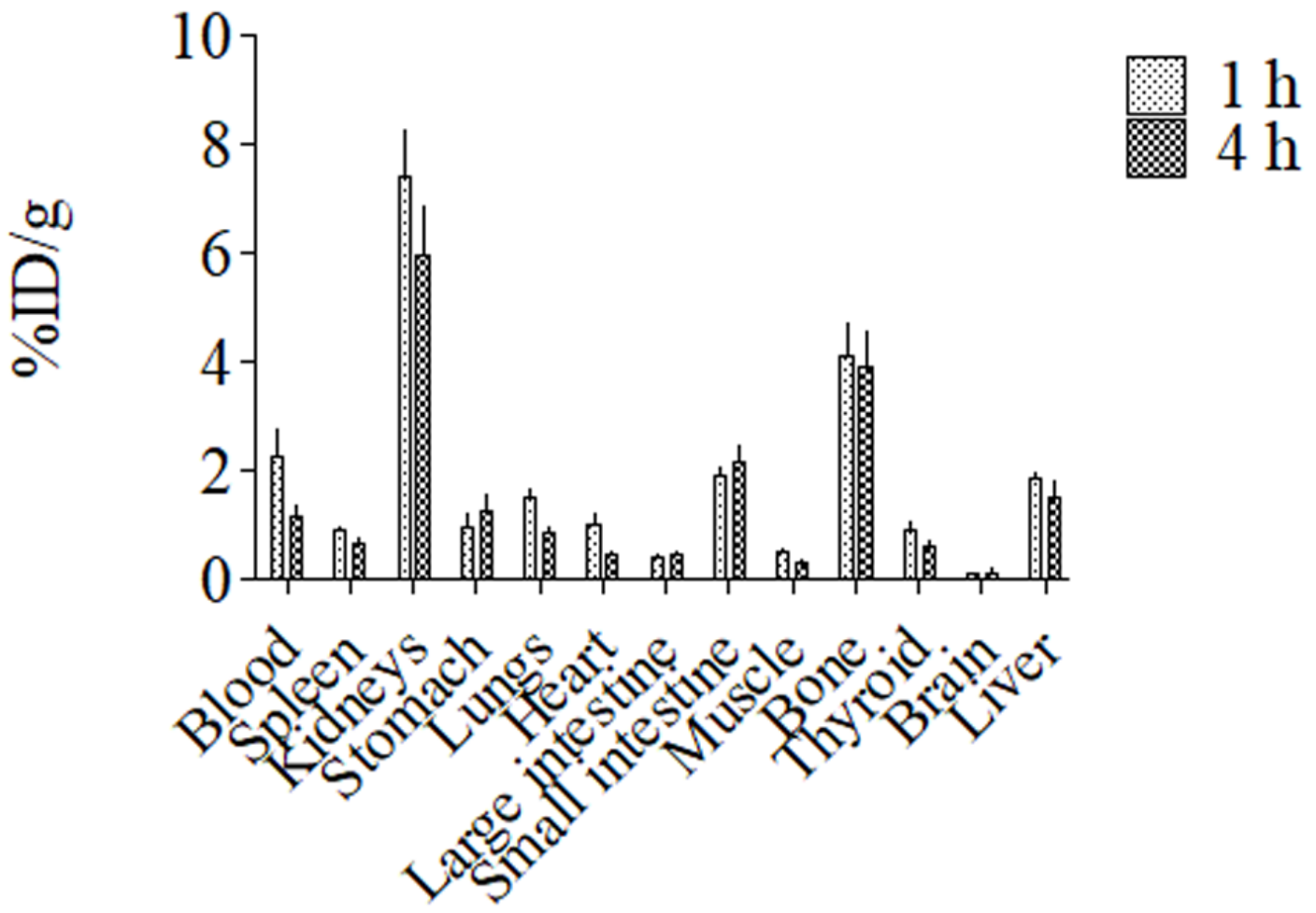

FIGURE 5 - Biodistribution profile of ${ }^{99 \mathrm{~m}} \mathrm{Tc}$-CDV following intravenous tail-vein administration in healthy female SWISS mice. All data are the mean percentage $(n=7)$ of the injected dose of ${ }^{99 m} \mathrm{Tc}-\mathrm{CDV}$ per gram of tissue \pm SD of the mean. 


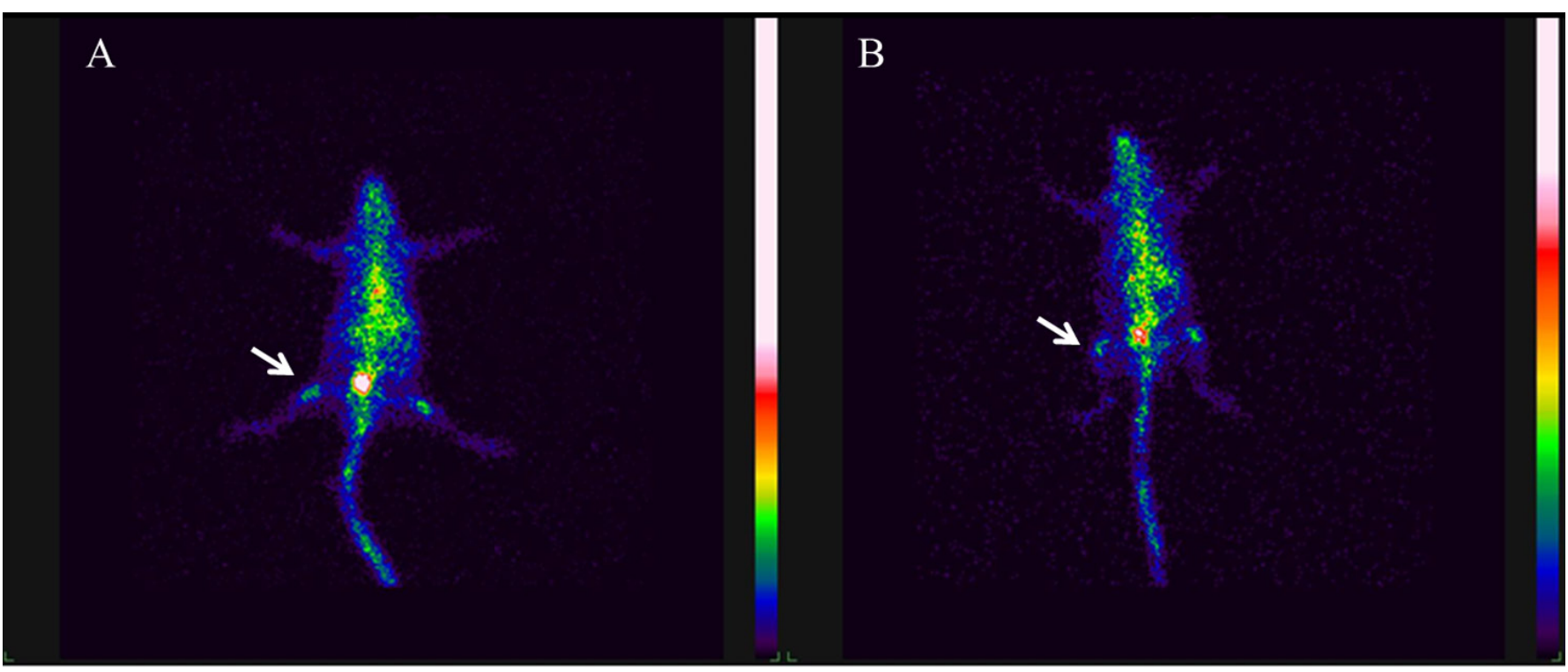

FIGURE 6 - Scintigraphic images obtained at 1 (a) and 4 (b) h after intravenous injection of ${ }^{99 m}$ Tc-CDV into healthy mice (n=7). The arrows indicate bone uptake.

it is currently the mainstay of antiviral therapy for adenovirus (Vora, Brothers, Englund, 2017). Indeed, there are several case series showing the efficacy of CDV in adenovirus pneumonia (Lee et al., 2017). It is known that intralesional CDV may help control papilloma regrowth and reduce disease severity in children with recurrent respiratory papillomatosis, as well (Goon et al., 2008).

The diverse chemistry of ${ }^{99 \mathrm{~m}} \mathrm{Tc}$ has led to the development of numerous ${ }^{99 \mathrm{~m}} \mathrm{Tc}$ radiopharmaceuticals suitable for various diagnostic procedures, since they will distribute, after being systemically administrated, and accumulate in the organ or tissue of interest according to their design (Papagiannopoulou, 2017). In this regard, considering there is still no published study on the radiolabeling of CDV, the aim of this study was to develop a radiotracer with ${ }^{99 \mathrm{~m}} \mathrm{Tc}$ in order to further evaluate the in vivo biodistribution of CDV.

After being purified from ${ }^{99 \mathrm{~m}} \mathrm{TcO} 2$, the stability of the complex ${ }^{99 \mathrm{~m}} \mathrm{Tc}-\mathrm{CDV}$ was evaluated and it showed stability over $90 \%$ in both saline and plasma, at all evaluated times. These results guarantee that, during all time of analysis, monitoring the behavior of ${ }^{99 \mathrm{~m}} \mathrm{Tc}$ reflects the behavior of CDV itself.

Blood clearance data show that blood levels of ${ }^{99 \mathrm{~m}} \mathrm{Tc}-$ CDV decays in a biphasic manner, showing a slow halflife of $227.1 \mathrm{~min}$. These results are in agreement with a previously published study, in which CDV showed a slow half-life of $5.8 \mathrm{~h}$ (Brown et al., 2015). The relatively long half-life of the ${ }^{99 \mathrm{~m}} \mathrm{Tc}-\mathrm{CDV}$, a small and hydrophilic complex, might explain the high plasma protein binding for ${ }^{99 \mathrm{~m}} \mathrm{Tc}-\mathrm{CDV}$, with a maximum of $88.9 \pm 0.0 \%$ at $1 \mathrm{~h}$ post-incubation. $\log \mathrm{P}$ of $-1.39 \pm 1.9$ found for ${ }^{99 \mathrm{~m}} \mathrm{Tc}-$ CDV also reflects the high hydrophilicity of the complex due to its polar character. It is worth mentioning, that, to the best of knowledge, this is the first report of radiolabeled CDV. The use of radiolabeled molecules is an exquisite strategy to track in vivo, at real time, the desired compound providing quantitative information about tissue distribution.

In this sense, we also performed biodistribution studies in healthy mice to predict the behavior of CDV after being administrated systemically. At 1 and $4 \mathrm{~h}$ post-administration, maximum uptake was observed in the kidneys, as expected, due to the high hydrophilicity of CDV, as demonstrated by its partition coefficient. In addition, this profile indicates a main renal excretion and might be related to the high nephrotoxicity of CDV, as previously described in the literature (Mareri et al., 2016). Furthermore, a high uptake was found in the bones. Bones are composed of various inorganic ions, mainly calcium and phosphate and, therefore, they show an affinity for compounds that present these ions. Even though CDV presents a phosphonate group instead of a phosphate one, both are very similar, which explains the bone uptake, as demonstrated before with 
MDP (methoxy diphosphonate), a radiopharmaceutical used to diagnose bone metastasis (Saeed et al., 2017). It is important to mention that small intestine and liver showed moderate uptake indicating the contribution of the intestinal route. Scintigraphic imaging of the mice corroborates with the biodistribution data found.

These results pose new perspectives to monitor CDV in vivo in real time in different experimental models to better understand drug behavior. Moreover, CDV has gained great attention in the pharmaceutical field since its applications, already mentioned, in several virus infections. As a result, many researchers have studied different formulations, nano- and microparticles to improve CDV efficiency (Santoyo et al., 2002). By using the novel radiotracer $\left({ }^{99 \mathrm{~m} T c-C D V}\right)$ it might be possible to evaluate the release profile of CDV in different formulations and compare innovative release systems with conventional ones. Thus, this work shows a promising tool for assessing CDV in both in vitro and in vivo assays.

\section{CONCLUSION}

Our feasibility study demonstrated that CDV can be successfully labeled with ${ }^{99 \mathrm{~m}} \mathrm{Tc}$, showing high and prolonged stability. In addition, in vitro assays showed a high plasma protein binding. In vivo assays confirmed a relatively slow half-life of CDV and its main renal excretion. In addition, scintigraphic imaging confirmed the results presented by the biodistribution studies. In summary, these results infer that ${ }^{99 \mathrm{~m}} \mathrm{Tc}-\mathrm{CDV}$ can be reliably used as a radiotracer to perform in vitro and in vivo studies.

\section{ACKNOWLEDGMENTS}

We wish to thank Conselho Nacional de Desenvolvimento Científico e Tecnológico (CNPqBrazil) for its financial support and fellowships.

\section{REFERENCES}

Andrei G, Snoeck R. Cidofovir activity against poxvirus infections. Viruses. 2010;2(12):2803-30.

Broekema FI, Dikkers FG. Side-effects of cidofovir in the treatment of recurrent respiratory papillomatosis. Eur Arch Oto-Rhino-Laryngology. 2008;265(8):871-9.
Brown AEC, Cohen MN, Tong S, Braverman RS, Rooney JF, Giller R, et al. Pharmacokinetics and safety of intravenous cidofovir for life-threatening viral infections in pediatric hematopoietic stem cell transplant recipients. Antimicrob Agents Chemother. 2015;59(7):3718-25.

Carifi M, Napolitano D, Morandi M, Dall'olio D. Recurrent respiratory papillomatosis: current and future perspectives. Ther Clin Risk Manag. 2015;11:731-738.

Coomes EA, Wolfe AI, Michelis FV, Kim DDH, Thyagu S, Viswabandya A, et al. Efficacy of cidofovir in treatment of BK virus induced hemorrhagic cystitis in post allogeneic hematopoietic cell transplant recipients. Biol Blood Marrow Transplant. 2018;24(9):1901-5.

De Barros ALB, Das Graças Mota L, De Aguiar Ferreira C, Corrêa NCR, De Góes AM, Oliveira MC, et al. ${ }^{99 \mathrm{~m} T c-l a b e l e d}$ bombesin analog for breast cancer identification. J Radioanal Nucl Chem. 2013;295(3):2083-90.

Fernandes RS, Silva J de O, Lopes SCA, Chondrogiannis S, Rubello D, Cardoso VN, et al. Technetium-99m-labeled doxorubicin as an imaging probe for murine breast tumor (4T1 cell line) identification. Nucl Med Commun. 2016;37(3):30712.

Fusconi M, Grasso M, Greco A, Gallo A, Campo F, Remacle $\mathrm{M}$, et al. Recurrent respiratory papillomatosis by HPV: review of the literature and update on the use of cidofovir. Acta Otorhinolaryngol Ital. 2014;34(6):375-81.

Goon P, Sonnex C, Jani P, Stanley M, Sudhoff H. Recurrent respiratory papillomatosis: An overview of current thinking and treatment. Eur Arch Oto-Rhino-Laryngology. 2008;265(2):147-51.

Jackowska J, Klimza H, Piersiala K, Wierzbicka M. Outcomes of bevacizumab and cidofovir treatment in HPVassociated and recurent respiratory papillomatosis - review of the literature. Otolaryngol Pol. 2018;72(4):1-8.

Lee M, Kim S, Kwon OJ, Kim JH, Jeong I, Son JW, et al. Treatment of Adenoviral Acute Respiratory Distress Syndrome Using Cidofovir With Extracorporeal Membrane Oxygenation. J Intensive Care Med. 2017;32(3):231-8.

Mareri A, Lasorella S, Iapadre G, Maresca M, Tambucci R, Nigro G. Anti-viral therapy for congenital cytomegalovirus infection: pharmacokinetics, efficacy and side effects. J Matern Neonatal Med. 2016;29(10):1657-64.

Papagiannopoulou D. Technetium-99m radiochemistry for pharmaceutical applications. J Label Compd Radiopharm. 2017;60(11):502-20. 
Rasmussen ER, Schnack DT, Jorkov AS, Raja AA, Oslen CH, Homoe P. Long-term follow-up and outcome in patients with recurrent respiratory laryngeal papillomatosis. Dan Med J. 2017;64(12):A5424.

Saeed S, Haq S ul, Sohaib M, Nawaz Khan A. Utility of Tc99m MDP bone SPECT in evaluation of osseous involvement in craniofacial malignancies. J Cranio-Maxillofacial Surg. 2017;45(11):1815-9.

Sahota RS, Uddin FJ, Al-Shukri J, Moir AA. Novel method of intralesional cidofovir injection into laryngotracheal papillomata. J Laryngol Otol. 2011;125(4):402-4.

Sala NP, Suriol AF, Montero ER. Intralesional cidofovir in human papilomavirus infection in interdigital spaces. Farm Hosp. 2017;41(1):132-3.

Santoyo S, De Jalón EG, Ygartua P, Renedo MJ, BlancoPríeto MJ. Optimization of topical cidofovir penetration using microparticles. Int J Pharm. 2002;242(1-2):107-13.
Snehalatha M, Venugopal K, Saha RN, Babbar AK, Sharma RK. Etoposide loaded PLGA and PCL nanoparticles II: Biodistribution and pharmacokinetics after radiolabeling with Tc-99m. Drug Deliv. 2008;15(5):277-87.

Tran MN, Galt L, Bashirzadeh F. Recurrent respiratory papillomatosis: the role of cidofovir. Respirol Case Reports. 2018;6(8):1-3.

Vora SB, Brothers AW, Englund JA. Renal toxicity in pediatric patients receiving cidofovir for the treatment of adenovirus infection. J Pediatric Infect Dis Soc. 2017;6(4):399-402.

Yang DJ, Kim C-G, Schechter NR, Azhdarinia A, Yu D-F, Oh C-S, et al. Imaging with ${ }^{99 \mathrm{~m}} \mathrm{Tc}$ ECDG targeted at the multifunctional glucose transport system: feasibility study with rodents. Radiology. 2003;226(15):465-73.

Received for publication on $12^{\text {th }}$ July 2018 Accepted for publication on $20^{\text {th }}$ December 2018 